\title{
Factors associated with stunting among children aged 6-59 months in Bensa District, Sidama Region, South Ethiopia: unmatched case-control study
}

\author{
Temesgen Tafesse ${ }^{1 *}$, Amanuel Yoseph ${ }^{2}$, Kaleb Mayiso ${ }^{2}$ and Taye Gari ${ }^{2}$
}

\begin{abstract}
Background: Stunting remains one of the most common malnutrition problems among children in Ethiopia. Identifying the risk factors of stunting assists health planners to prioritize prevention strategies, and is a fundamental step for intervention. Therefore, this study aimed to assess factors associated with stunting among children aged 6-59 months in Bensa district, Sidama Region, South Ethiopia, 2018.

Methods: A facility-based unmatched case-control study was conducted from January 10 to March 10, 2018, on a sample of 237(79 cases and 158 controls) children aged 6-59 months with their respective mothers/caretakers. Data were collected using a structured, face-to-face interviewer-administered questionnaire and standard physical measurements. The data were entered into EP INFO version 7 and WHO Anthro software and analyzed using SPSS version 20. The variables were entered into the multivariable model using the backward stepwise regression approach. Multivariable logistic regression analysis was used to identify factors associated with stunting. Adjusted odds ratio (AOR) with $95 \%$ confidence interval $(95 \% \mathrm{Cl})$ and $p$-value $<0.05$ was used to declare the significance.
\end{abstract}

Results: Sex distribution was almost equal (Males $=52.3 \%$, Females $=47.7 \%$ ). The mean (standard deviation) age of cases and controls was $27.35( \pm 12.71)$ and 28.70 ( \pm 13.27$)$ months respectively.

The risk factors for stunting were diarrhea in the past two weeks ( $A O R=2.71,95 \% \mathrm{Cl}: 1.42-5.16)$, being male $(A O R=2.37,95 \% \mathrm{Cl}: 1.224-4.59)$, inappropriate exclusive breastfeeding ( $\mathrm{AOR}=2.07,95 \% \mathrm{Cl}: 1.07-4.01)$, having less than or equal to three under-five children in the household ( $A O R=2.18,95 \% \mathrm{Cl}: 1.03-4.64)$, and mothers who had no formal education ( $\mathrm{AOR}=3.28,95 \% \mathrm{Cl}: 1.56-6.924$ ).

Conclusions: Diarrhea in the past two weeks, sex of a child, inappropriate exclusive breastfeeding, number of underfive children in the household, and mothers who had no formal education were the risk factors of stunting. Thus organized efforts aimed at focus on prevention of diarrhea as part of an overall public health strategy for improving child health and nutrition. Educating mothers/caretakers on the importance of exclusive breastfeeding should be considered. Moreover, mothers need to be encouraged to space birth between children through the use of family planning services.

Keywords: Children aged 6-59 months, stunting, unmatched case-control, Bensa district, Ethiopia

\footnotetext{
*Correspondence: temesgentfss@gmail.com; hawassaug2019@gmail.com

1 Department of Public Health, Hawassa University Daye Branch, Hawassa,

Ethiopia

Full list of author information is available at the end of the article
}

(C) The Author(s) 2021. Open Access This article is licensed under a Creative Commons Attribution 4.0 International License, which permits use, sharing, adaptation, distribution and reproduction in any medium or format, as long as you give appropriate credit to the original author(s) and the source, provide a link to the Creative Commons licence, and indicate if changes were made. The images or other third party material in this article are included in the article's Creative Commons licence, unless indicated otherwise in a credit line to the material. If material is not included in the article's Creative Commons licence and your intended use is not permitted by statutory regulation or exceeds the permitted use, you will need to obtain permission directly from the copyright holder. To view a copy of this licence, visit http://creativecommons.org/licenses/by/4.0/. The Creative Commons Public Domain Dedication waiver (http://creativeco mmons.org/publicdomain/zero/1.0/) applies to the data made available in this article, unless otherwise stated in a credit line to the data. 


\section{Background}

One form of malnutrition is chronic malnutrition or stunting reflects a process of failure to reach linear growth potential. Stunting is defined as a height/length for age is less than -2 SD of the median of the NCHS/ WHO international reference. It starts at the beginning of life and lasts throughout their lifetime $[1,2]$.

Stunting is likely driven by a deficit of essential proteins and micronutrients at the cellular level and chronic inflammation, which reduces the concentration of insulin-like growth factor 1 that is required for linear growth [3]. It is the most prevalent form of malnutrition.

According to the global nutrition report, it was estimated that 150.8 million children had stunted globally in 2017. Regionally, South Asia is home to $38.9 \%$ of the world's stunted children, having the highest burden of the regions. Stunting has declined in Latin America and the Caribbean from 16.9 to $9.6 \%$; and Africa from 38.3 to $30.3 \%$ [4]. The burden of stunting is a major public health problem in developing countries (Africa and South Asia) which accounts for two-thirds of the burden [5]. It is also a highly prevalent problem in Ethiopia. According to the Ethiopian DHS 2016 report, 38\% of under-five children were stunted. Similarly, the high prevalence was reported in South Ethiopia 38.6\% [6]. A study conducted in the region showed that the prevalence of child stunting was $41 \%$ [7].

Malnutrition is responsible for more than one-third of child deaths and $11 \%$ of the global total disease burden [8]. The economic cost of stunting is high which leads total loss of $15 \%$ disability-adjusted life years [9]. It has also resulted in a loss of adult height by $1 \%$. Consequently, childhood stunting might end up with $1.4 \%$ losses in productivity [10].

Health consequences of stunting are delay in physical growth and motor development, and susceptibility to contracting diseases. Later in life, it increases the risk of being overweight and developing associated chronic diseases such as cardiovascular disease, diabetes, cancer, and mental health disorders $[11,12]$.

Malnutrition is the result of a long sequence of interlinked events. The most frequently suggested causes of malnutrition are: Immediate cause, underlying cause, and basic cause. The immediate causes are poor diet and disease which are themselves caused by underlying determinants; household food security, maternal/child-caring practices, and access to health services, and a healthy environment. Underlying factors themselves are influenced by the basic causes; socio-economic and political conditions [13]. Thus, two main pathways are described leading to a child's growth failure: inadequate nutrition and exposure to infection/inflammation [14].
Sustainable Development Goals (SDGs) contain indicators that are highly relevant for nutrition, reflecting nutrition is a central role in sustainable development. Global nutrition target for 2025 to reduce the number of stunted children by $40 \%$ [15].

Ethiopia had established rural development extension strategies and related programs to address the malnutrition problem. The outcomes of initiatives are encouraging but, not sufficient due to a lack of coordination among the relevant sectors. In addition, Ethiopia launched an ambitious and revised National Nutrition Plan (NNP) primarily focused on the first 1000 days and accelerated stunting reduction actions. It was also targeted to reduce the prevalence of stunting from 44.4 to 20\% [16]. Thus, the Food and Nutrition Policy (FNP) was developed with the involvement of relevant stakeholders to address the food and nutrition security challenges of the country through multi-sectoral integration and collaboration. It aims to end child stunting in Ethiopia [17]. However, under-nutrition remains one of the child health problems and poses a significant obstacle to achieving better child health outcomes [18].

There is limited information on factors associated with stunting among children aged 6-59 months in Bensa district, Sidama Region, South Ethiopia. In addition, information is also important because of the target for Second Growth and Transformation Plan (GTPII) in 2020 [19]. And also the preparation for the third Growth and transformation plan in Ethiopia is fast approaching and the findings from this study serve as baseline information. Moreover, assessing and identifying the risk factors for stunting is important to guide public health planners, policymakers, and implementers to plan and design appropriate intervention strategies to enhance the nutritional status of the children. Therefore, the main aim of this study is to assess factors associated with stunting among children aged 6-59months in Bensa district, Sidama Region, South Ethiopia.

\section{Methods \\ Study setting, design, and population}

A facility-based unmatched case-control study was carried out in Bensa district from January 10 to March 10, 2018. Bensa district is located $400 \mathrm{~km}$ from Addis Ababa, the capital of Ethiopia. It is also $131 \mathrm{~km}$ from Hawassa, the capital of Sidama Region. According to the 2018 central statistical agency report of Ethiopia, the total population of the district was estimated to be $310,952(8.1 \%$ urban and $91.9 \%$ rural). Of these, $13.94 \%$ were children in the age group of 6-59 months. The district has consisted of 03 urban and 34 rural Kebeles (smallest administrative unit of Ethiopia). The health service coverage of the district was $94 \%$. There are a one-government primary 
hospital, 11 health centers, and 37 health posts. It has also consisted of 4 private clinics and 12 pharmacies in the districts. According to the health department report, the distribution of stunting affects almost all Kebeles of the district.

The source population of this study was all children in the age group of 6-59 months (pair with their mothers/ caretakers) who were utilized EPI (Expanded Program for Immunization) and under-five OPD (Out Patient Department) service in Bensa district health facilities. The sample population was all selected children in the age group of 6-59 months (pair with their mothers/caretakers) in selected health facilities who have lived with the child at least for 6 months. Those children who were very sick requiring emergency treatment were excluded from this study.

\section{Sample size determination and sampling technique}

The sample size was calculated by using a two population proportion formula in consideration of the following assumptions: the proportion of children who were sick every month be $14.6 \%$ for controls and of the cases $32.4 \%$, level of confidence $95 \%$, power of the study $80 \%$, a ratio of controls over cases 2:1 to detect an odds ratio of 2.8 [20]. Thus, the final sample size after adding a $10 \%$ non-response rate is 237 (79 cases and 158 controls). In Bensa district, there is 1 primary hospital and 11 health centers. One primary Hospital and three Health centers were selected out of eleven health centers by simple random sampling technique (lottery method). The calculated sample size (237) was proportionally allocated to the selected health facilities. A consecutive sampling technique was used to select the study participants until the calculated sample size was attained. All children aged 6 to 59 months visiting hospital and health centers during the data collection period were measured for their height. Then, children were categorized as stunted or non-stunted based on the calculated z-score value. First, stunted children were identified and then selected as cases. The controls were children aged 6 to 59 months without stunting from the same facility cases where selected.

\section{Data collection method and tools}

The data collection was administered by 9 Bsc nurses. One health officer and the principal investigator intensively supervised the data collection process. The data collectors were collected information related to factors associated with stunting by interviewing the mothers/ caretakers face to face. A structured questionnaire and anthropometric measurement were used to collect data. Interviews were conducted with mothers/caretakers of the children to fill the questionnaire and were impossible to get them or if there is refusal, the next client was considered for the study. Data collection was conducted in a stepwise manner in each health facility in their respective schedule.

\section{Anthropometric measurements}

The body length of children aged 6-24 months was measured without shoes and the length will read to the nearest $0.1 \mathrm{~cm}$. The mother helped to measure the recumbent length of her child and this was done by using a portable horizontal wooden length board. However, the height of children aged 24-59 months was measured using a vertical wooden height board by placing the child on the measuring board, and the child standing upright in the middle of the board. The child's head, shoulders, buttocks, knees, and heels touch the board.

\section{Data quality control}

Data were collected using a structured, face-to-face interviewer-administered questionnaire and standard physical measurements. To ensure the quality of data pre-tested was done on $5 \%$ of samples in the non-selected health facility. A pre-tested questionnaire was prepared in English and translated into the local Sidamigna language and retranslated back to English to ensure consistency. The training was given to data collectors and supervisor by the principal investigator for two days. The training was focused on the objectives of the study and data collection method, anthropometric measurement, and data recording. Regular checkups for completeness and consistency of the data were made daily.

\section{Study variables}

The outcome variable (Height/length for age z-score, Stunting).

Independent variables included Socio-demographic variables(marital status, residence, ethnicity, religion, number of under-five children, family size, parent's education status, occupation, and economic status), Child characteristics (age, sex, birth order, birth interval, place of delivery, types of birth, and morbidly status), Child caring practices (feeding and immunization), maternal characteristics(age, mothers' age during first child, number of children ever have born, ANC visits, use of extra food during pregnancy or lactation and family planning), environmental Health condition (water, hygiene, and sanitation).

\section{Operational definitions}

Stunting (chronic malnutrition): means HFA is below -2 SD of the reference population while below -3 SD indicates severe stunting. Controls: were defined as 
study subjects who had an anthropometric reading with z-scores $\geq-2$ SD [2].

Duration of breastfeeding: the number of months of breastfeeding among children.

Complementary foods: are foods which are required by the child after six months of age.

Diarrhea: a child with loose stools three or more times in a day.

Family size: refers to the total number of people living in a house during the study period.

\section{Data processing and analysis}

The data were entered into EP INFO version 7 and WHO Anthro software and analyzed using SPSS version 20. The wealth index was constructed by using Principal Components Analysis in SPSS. All required variables recording and computations were done before the main analysis. Descriptive analyses such as mean, standard deviation, proportion were conducted to obtain descriptive measures for the socio-demographic characteristics and other variables.

Binary logistic regression was used to identify factors associated with stunting. The bi-variable logistic regression analysis started with unadjusted analysis in which each potential predictor was assessed separately for its association with stunting [21]. Variables with p-values $<0.25$ on the unadjusted analysis were entered into a multivariable logistic regression model to find out independent risk factors of stunting adjusting for other factors in the model.

Moreover, multicollinearity was checked by using the collinearity diagnostic test by checking the value of the Variance Inflation Factor (VIF) and tolerance test. In this study, the maximum VIF became 4.71 while the tolerance value was greater than 0.1 , which proved the absence of multicollinearity between the independent variables. Hosmer-Lemeshow goodness-of-fit was used to test for the model fitness, and the p-value for the Hosmer-Lemeshow test was 0.49 which indicates a good model.

Odds ratio at $95 \% \mathrm{CI}$ were used to measure the strength of association between outcome and predictor variables. $P$-value $<0.05$ was considered to declare statistical significance in multivariate logistic regression analysis. Finally, the results were presented in texts and tables.

\section{Results}

\section{Socio-economic and demographic characteristics of the parents}

A total of 237 participants have participated in the study with a response rate of $100 \%$. The majority of study subjects were Sidama in both groups; 75 (94.9\%) of cases and $154(97.5 \%)$ of controls. Similarly, 74 (93.7\%) mothers of children in cases and 151 (95.6\%) in controls were protestant in religion. Mothers of 45 (57.0\%) of cases and 48 (30.4\%) controls had no formal education. Households who had less than or equal to three under-five children were $40(50.6 \%)$ and 47 (29.7\%) of cases and controls respectively. Similarly, the family size was five and above for $46(58.2 \%)$ of cases and 70 (44.3\%) of controls (Table 1).

\section{Child characteristics}

The mean age of cases and controls was $27.35( \pm 12.71)$ and $28.70( \pm 13.27)$ months respectively. The largest proportion of cases $(30.4 \%)$ and controls $(27.8 \%)$ of the children were found in 12-23 months age groups. Among the cases, $65.8 \%$ were male and $45.6 \%$ were females. More than half $(54.4 \%)$ of cases and $67.1 \%$ controls were delivered at the health facility. Among the study participants, 44 (55.7\%) of cases and 51 (32.3\%) of controls had diarrhea in the past 2 weeks before the survey (Table 2).

\section{Child care practices}

Of all mothers of children in the cases group, 50 (63.3\%) and in the controls group, 118(74.7\%) started breastfeeding within the first one hour after birth. The exclusive breastfeeding rate for 6 months were 34 (43.0\%) and 106 (67.1\%) for cases and controls respectively. Meanwhile, the duration of breastfeeding was less than 2 years for 46 (58.2\%) and $86(54.4 \%)$ of cases and controls respectively. Concerning immunization status $67(84.4 \%)$ of cases and $146(92.4 \%)$ of controls were vaccinated, and 35(44.3\%) of cases and 90(57.0\%) of controls were received deworming services (Table 3 ).

\section{Maternal characteristics}

The mean age for mothers of the cases was $29.25( \pm 5.88)$ while it was $27.30( \pm 5.17)$ for the mothers of the controls. Mothers of $33(41.8 \%)$ of cases and 40 (25.3\%) of controls had given birth of 4 and above children. Mothers of $52(65.8 \%)$ of cases and $82(51.9 \%)$ of controls didn't consume extra food during pregnancy and lactation. About 62 (78.5\%) and 132 (83.5\%) of mothers visited health facilities for antenatal care during their pregnancy period for both cases and controls respectively. Concerning family planning, mothers of $61(77.2 \%)$ of cases and $125(79.1 \%)$ of controls were every used family planning (Table 4).

\section{WASH condition of study participants}

Children of households who used unprotected sources of water for drinking accounts $32(40.5 \%)$ and 43 (27.2\%) in cases and controls respectively. Those children households who didn't treat water by any means were found to be $61(77.2 \%)$ in cases and $113(71.5 \%)$ in controls. The 
Table 1 Socio-economic and demographic characteristics of study participants in Bensa district, Sidama Region, South Ethiopia, 2018

\begin{tabular}{|c|c|c|c|c|c|c|}
\hline \multirow[t]{2}{*}{ Variables Category } & & \multicolumn{2}{|c|}{ Cases $(n=79)$} & \multicolumn{2}{|c|}{ Controls $(n=158)$} & \multirow[t]{2}{*}{$P$-value } \\
\hline & & Frequency & $\%$ & Frequency & $\%$ & \\
\hline \multirow[t]{2}{*}{ Religion } & Protestant & 74 & 93.7 & 151 & 95.6 & .530 \\
\hline & Others $^{\mathrm{a}}$ & 5 & 6.3 & 7 & 4.4 & \\
\hline \multirow[t]{2}{*}{ Ethnicity } & Sidama & 75 & 94.9 & 154 & 97.5 & .309 \\
\hline & Others $^{b}$ & 4 & 5.1 & 4 & 2.5 & \\
\hline \multirow[t]{2}{*}{ Residence } & Rural & 66 & 83.5 & 120 & 75.9 & .180 \\
\hline & Urban & 13 & 16.5 & 38 & 24.1 & \\
\hline \multirow[t]{2}{*}{ Household head } & Father & 52 & 65.5 & 72 & 45.6 & .360 \\
\hline & Mother & 27 & 34.2 & 86 & 54.4 & \\
\hline \multirow[t]{2}{*}{ Marital status } & Married & 73 & 92.4 & 150 & 94.9 & .436 \\
\hline & Others ${ }^{c}$ & 6 & 7.0 & 8 & 5.1 & \\
\hline \multirow[t]{2}{*}{ Family size } & $<5$ & 33 & 41.8 & 88 & 55.7 & .043 \\
\hline & $\geq 5$ & 46 & 58.2 & 70 & 44.3 & \\
\hline \multirow[t]{2}{*}{ Number of $<5 \mathrm{yr}$ children } & 1 & 39 & 49.4 & 111 & 70.3 & .002 \\
\hline & $2-3$ & 40 & 50.6 & 47 & 29.7 & \\
\hline \multirow[t]{4}{*}{ Educational status of mother } & Has no formal education & 45 & 57.0 & 48 & 30.4 & .001 \\
\hline & Can read and write & 9 & 11.4 & 11 & 7.0 & \\
\hline & Primary $(1-8)$ & 13 & 16.4 & 72 & 45.6 & \\
\hline & Secondary \& above & 12 & 15.2 & 27 & 17.1 & \\
\hline \multirow[t]{4}{*}{ Educational status of father } & Has no formal education & 14 & 17.7 & 18 & 11.4 & .130 \\
\hline & Can read and write & 12 & 15.2 & 15 & 9.5 & \\
\hline & Primary(1-8) & 34 & 43.0 & 67 & 42.4 & \\
\hline & Secondary \& above & 19 & 24.0 & 58 & 36.7 & \\
\hline \multirow[t]{2}{*}{ Mother's occupation } & Housewives & 66 & 83.5 & 134 & 84.8 & .800 \\
\hline & Others $^{d}$ & 13 & 16.5 & 24 & 15.2 & \\
\hline \multirow[t]{2}{*}{ Father's occupation } & Farmers & 57 & 72.2 & 96 & 60.8 & .084 \\
\hline & Others $^{d}$ & 22 & 27.8 & 62 & 39.2 & \\
\hline \multirow[t]{3}{*}{ Economic status of families } & Poor & 41 & 51.9 & 53 & 33.5 & .008 \\
\hline & Medium & 17 & 21.5 & 32 & 20.3 & \\
\hline & Rich & 21 & 26.6 & 73 & 46.2 & \\
\hline
\end{tabular}

Key: ${ }^{a}=$ Muslim, Orthodox, Catholic; ${ }^{b}=$ Oromo, Amhara, Gurage, Wolayta; ${ }^{c}=$ single, divorced, widowed ${ }^{\mathrm{d}}=$ merchant/Trade, private org. employee, daily laborer, a government employee

majority of children of $\mathrm{HHs}, 73(92.4 \%)$ of cases, and 148 (93.7\%) of controls have a latrine. (Table 5).

\section{Factors associated with stunting among children aged 6-59 months}

In the bivariate analysis, the number of under-five year's children in the households, sex of a child, mothers' educational status, economic status of a family, total family size, diarrhea last $2 \mathrm{wks}$, inappropriate exclusive breastfeeding, and source of drinking water had a significant association with stunting.

The multivariable model rivaled that children living in households less than or equal to three under-five children were 2.18 times more likely to develop stunting as compared to those living in households with one under-five child (AOR $=2.18,95 \% \mathrm{CI}: 1.03-4.64$ ). The odds of stunting in male children were 2.4 times higher as compared to females ( $\mathrm{AOR}=2.37,95 \%: 1.224-4.59$ ).

This model also showed that children whose mothers have no formal education were 3.28 times more likely to be stunted as compared to mothers with formal education (AOR $=3.28,95 \% \mathrm{CI}: 1.56-6.924)$. Children who inappropriately exclusively breastfeed were 2.07 times more likely to develop stunting than children who were exclusively breastfed for the first 6 months $(\mathrm{AOR}=2.07$, 95\% CI: 1.07-4.01). Children with exposure to diarrhea last 2 weeks were 2.71 times more likely to be stunted when compared with those children with no diarrheal exposure (AOR $=2.71,95 \% \mathrm{CI}: 1.42-5.16)$ (Table 6). 
Table 2 Child characteristics among children aged 6-59 months in Bensa district, Sidama Region, South Ethiopia, 2018

\begin{tabular}{|c|c|c|c|c|c|c|}
\hline \multirow[t]{2}{*}{ Variables } & \multirow[t]{2}{*}{ Category } & \multicolumn{2}{|c|}{ Cases $(n=79)$} & \multicolumn{2}{|c|}{ Controls $(n=158)$} & \multirow[t]{2}{*}{$P$-value } \\
\hline & & Frequency & $\%$ & Frequency & $\%$ & \\
\hline \multirow[t]{2}{*}{ Sex of children } & Male & 52 & 65.8 & 72 & 45.6 & .003 \\
\hline & Female & 27 & 34.2 & 86 & 54.4 & \\
\hline \multirow[t]{5}{*}{ Age in months } & $6-11$ & 7 & 8.9 & 16 & 10.1 & .993 \\
\hline & $12-23$ & 24 & 30.4 & 44 & 27.8 & \\
\hline & $24-35$ & 20 & 25.3 & 40 & 25.3 & \\
\hline & $36-47$ & 19 & 24.1 & 40 & 25.3 & \\
\hline & $48-59$ & 9 & 11.4 & 18 & 11.4 & \\
\hline \multirow[t]{3}{*}{ Birth order } & 1 & 19 & 24.1 & 61 & 38.6 & .003 \\
\hline & $2-3$ & 27 & 34.2 & 63 & 39.9 & \\
\hline & $\geq 4$ & 33 & 41.8 & 34 & 21.5 & \\
\hline \multirow[t]{2}{*}{ Place of delivery } & Home & 36 & 45.6 & 52 & 32.9 & .057 \\
\hline & Health facility & 43 & 54.4 & 106 & 67.1 & \\
\hline \multirow[t]{2}{*}{ Home delivery by } & TBA & 6 & 16.7 & 7 & 13.5 & .677 \\
\hline & Neighbors & 30 & 83.3 & 45 & 86.5 & \\
\hline \multirow[t]{2}{*}{ Birth type } & Single & 78 & 98.7 & 155 & 98.1 & .721 \\
\hline & Multiple & 1 & 1.3 & 3 & 1.9 & \\
\hline \multirow[t]{3}{*}{ Birth interval } & $<2$ year & 19 & 24.1 & 25 & 15.8 & .013 \\
\hline & $\geq 2$ & 47 & 59.5 & 79 & 50.0 & \\
\hline & No previous birth & 13 & 16.5 & 54 & 34.2 & \\
\hline \multirow[t]{2}{*}{ Diarrhea, last 2wks } & No & 35 & 44.3 & 107 & 67.7 & .001 \\
\hline & Yes & 44 & 55.7 & 51 & 32.3 & \\
\hline \multirow[t]{2}{*}{ Fever, last 2wks } & No & 47 & 59.5 & 113 & 71.5 & .062 \\
\hline & Yes & 32 & 40.5 & 45 & 28.5 & \\
\hline \multirow[t]{2}{*}{ ARI, last 2wks } & No & 72 & 91.1 & 134 & 84.8 & .173 \\
\hline & Yes & 7 & 8.9 & 24 & 15.2 & \\
\hline
\end{tabular}

\section{Discussion}

In this study factors associated with stunting were having less than or equal to three under-five children in the household, male sex, mothers who had no formal education, inappropriate exclusive breastfeeding, and exposure to diarrheal diseases in the last 2 weeks preceding the survey.

In this study participants living in households with less than or equal to three under-five children are more likely to develop stunting as compared to those living in households with one under-five child. This finding is similar with the studies conducted in Gurage Zone, Mekelle City, and Mozambique [22-24]. This might be the fact that as the number of under-five children increases in the household; the care given to the children decreases, mothers are unable to optimally breastfeed children, causes competition on family resources, and increases the risk of infectious diseases [25].

From this study finding, the odds of stunting are significantly higher in male children than females. This result is consistent with studies done in Lasta district, Korahay Zone, Dollo ado district, multi-level analysis in Ethiopia,
Southwest Uganda, and Indonesia [26-31]. The cause of this difference in sex requires further study, but variation might be due to the sex preference of the family. Additionally, it is believed that boys to be biologically more vulnerable to morbidity [32]. In contrast, a study conducted in Merhabete district, and Pakistani showed that female children were more stunted compared to male children [33, 34]. But this discrepancy could not be important to design interventions; because sex is a nonmodifiable risk factor.

Children whose mothers had no formal education were more likely to be stunted as compared to have a formal education. This study is in line with studies conducted in Hossana Town, rural Uganda, Iran, Kenya, and Padang city [35-39]. Mother's education affects the knowledge and attitude of parents which in turn affect their fertility behavior, use of health services, and access to nutritionrelated information. And also maternal education influences the preparation, procurement, and selection of nutritious foods for themselves and their children. The cumulative effect of these can have an impact on the prevention of stunting [40]. 
Table 3 Child caring practices of mothers/caretakers of children aged 6-59 months in Bensa district, Sidama Region, South Ethiopia, 2018

\begin{tabular}{|c|c|c|c|c|c|c|}
\hline \multirow[t]{2}{*}{ Variables } & \multirow[t]{2}{*}{ Category } & \multicolumn{2}{|c|}{ Cases $(n=79)$} & \multicolumn{2}{|c|}{ Controls $(n=158)$} & \multirow[t]{2}{*}{$P$-value } \\
\hline & & Frequency & $\%$ & Frequency & $\%$ & \\
\hline \multirow[t]{2}{*}{ Breast milk initiated after delivery } & Immediately & 50 & 63.3 & 118 & 74.7 & .069 \\
\hline & After 1 to $24 \mathrm{~h}$ & 29 & 36.7 & 40 & 25.3 & \\
\hline \multirow[t]{2}{*}{ Pre-lactation food/fluid } & No & 69 & 87.3 & 136 & 86.1 & .788 \\
\hline & Yes & 10 & 12.7 & 22 & 13.9 & \\
\hline \multirow[t]{2}{*}{ Type of pre-lactation food/fluid } & Water & 5 & 50 & 10 & 45.5 & .811 \\
\hline & Others $^{\mathrm{a}}$ & 5 & 50 & 12 & 54.5 & \\
\hline \multirow[t]{2}{*}{ Duration of EBF } & $<6$ or $>6$ months & 45 & 57.0 & 52 & 32.9 & .001 \\
\hline & 6 months & 34 & 43.0 & 106 & 67.1 & \\
\hline \multirow[t]{2}{*}{ Complimentary Feeding } & $<6$ or $>6$ months & 45 & 57.0 & 52 & 32.9 & .001 \\
\hline & 6 months & 34 & 43.0 & 106 & 67.1 & \\
\hline \multirow[t]{3}{*}{ Frequency of feeding/day } & 2 times & 13 & 16.5 & 20 & 12.7 & .607 \\
\hline & 3 times & 36 & 45.6 & 69 & 43.7 & \\
\hline & $\geq 4$ times & 30 & 38.0 & 69 & 43.7 & \\
\hline \multirow[t]{3}{*}{ Method used for feeding } & Bottle & 21 & 26.6 & 28 & 17.7 & .274 \\
\hline & Hand & 19 & 24.1 & 40 & 25.3 & \\
\hline & Spoon and Cup & 39 & 49.4 & 90 & 57.0 & \\
\hline \multirow[t]{2}{*}{ Duration of $B / F$} & $<24$ months & 46 & 58.2 & 86 & 54.4 & .579 \\
\hline & $\geq 24$ months & 33 & 41.8 & 72 & 45.6 & \\
\hline \multirow[t]{2}{*}{ Immunization } & No & 12 & 15.2 & 12 & 7.6 & .068 \\
\hline & Yes & 67 & 84.4 & 146 & 92.4 & \\
\hline \multirow[t]{2}{*}{ VAS } & No & 15 & 19.0 & 17 & 10.8 & .081 \\
\hline & Yes & 64 & 81.0 & 141 & 89.2 & \\
\hline \multirow[t]{2}{*}{ Deworming } & No & 44 & 55.7 & 68 & 43.0 & .066 \\
\hline & Yes & 35 & 44.3 & 90 & 57.0 & \\
\hline
\end{tabular}

Key: ${ }^{\mathrm{a}}=$ Milk, Butter, Hamesa

Table 4 Maternal characteristic of children aged 6-59 months in Bensa district, Sidama Region, South Ethiopia, 2018

\begin{tabular}{|c|c|c|c|c|c|c|}
\hline \multirow[t]{2}{*}{ Variables } & \multirow[b]{2}{*}{ Category } & \multicolumn{2}{|c|}{ Cases $(n=79)$} & \multicolumn{2}{|c|}{ Controls $(n=158)$} & \multirow[t]{2}{*}{$P$-value } \\
\hline & & Frequency & $\%$ & Frequency & $\%$ & \\
\hline \multirow[t]{3}{*}{ Mothers age } & $<20$ years & 7 & 8.9 & 17 & 10.8 & .127 \\
\hline & 20-35years & 60 & 75.9 & 130 & 82.3 & \\
\hline & $>35$ years & 12 & 15.2 & 11 & 7.0 & \\
\hline \multirow[t]{2}{*}{ Mothers age during first child } & $<21$ years & 60 & 75.9 & 110 & 69.6 & .308 \\
\hline & $\geq 21$ years & 19 & 24.1 & 48 & 30.4 & \\
\hline \multirow[t]{2}{*}{ Number of children } & $<4$ & 46 & 58.2 & 118 & 74.7 & .010 \\
\hline & $\geq 4$ & 33 & 41.8 & 40 & 25.3 & \\
\hline \multirow[t]{2}{*}{ Extra food during pregnancy and lactation } & No & 52 & 65.8 & 82 & 51.9 & .041 \\
\hline & Yes & 27 & 34.2 & 76 & 48.1 & \\
\hline \multirow[t]{2}{*}{ ANC for this child } & No & 17 & 21.5 & 26 & 16.5 & .340 \\
\hline & Yes & 62 & 78.5 & 132 & 83.5 & \\
\hline \multirow[t]{2}{*}{ F/P every used } & No & 18 & 22.8 & 33 & 20.9 & .737 \\
\hline & Yes & 61 & 77.2 & 125 & 79.1 & \\
\hline
\end{tabular}


Table 5 WASH conditions of mothers/caretakers of children aged 6-59 months in Bensa district, Sidama Region, South Ethiopia, 2018

\begin{tabular}{|c|c|c|c|c|c|c|}
\hline \multirow[t]{2}{*}{ Variables } & \multirow[t]{2}{*}{ Category } & \multicolumn{2}{|c|}{ Cases $(n=79)$} & \multicolumn{2}{|c|}{ Controls $(n=158)$} & \multirow[t]{2}{*}{$P$-value } \\
\hline & & Frequency & $\%$ & Frequency & $\%$ & \\
\hline \multirow[t]{2}{*}{ Drinking water source } & Unprotected ${ }^{\mathrm{a}}$ & 32 & 40.5 & 43 & 27.2 & \multirow[t]{2}{*}{.038} \\
\hline & Protected $^{b}$ & 47 & 59.5 & 115 & 72.8 & \\
\hline \multirow[t]{2}{*}{ Treat water by any means } & No & 61 & 77.2 & 113 & 71.5 & \multirow[t]{2}{*}{.349} \\
\hline & Yes & 18 & 22.8 & 45 & 28.5 & \\
\hline \multirow[t]{2}{*}{ Having latrine } & No & 6 & 7.6 & 10 & 6.3 & \multirow[t]{2}{*}{.714} \\
\hline & Yes & 73 & 92.4 & 148 & 93.7 & \\
\hline \multirow[t]{2}{*}{ Wash hand after toilet } & No & 15 & 19.0 & 39 & 24.7 & \multirow[t]{2}{*}{.324} \\
\hline & Yes & 64 & 81.0 & 119 & 75.3 & \\
\hline \multirow[t]{3}{*}{ The material used to wash hands after toilet } & Using water only & 34 & 53.1 & 55 & 46.2 & \multirow[t]{3}{*}{.096} \\
\hline & Water and soap & 20 & 31.2 & 54 & 45.4 & \\
\hline & Water and ashe & 10 & 15.6 & 10 & 8.4 & \\
\hline \multirow[t]{2}{*}{ Flush toilet } & No & 58 & 73.4 & 96 & 60.8 & \multirow[t]{2}{*}{.054} \\
\hline & Yes & 21 & 26.6 & 62 & 39.2 & \\
\hline \multirow[t]{4}{*}{ The method used for disposal of HHs waste } & Open field & 16 & 20.3 & 18 & 11.4 & \multirow[t]{4}{*}{.113} \\
\hline & In-pit & 16 & 20.3 & 46 & 46 & \\
\hline & Composting & 41 & 51.9 & 74 & 74 & \\
\hline & Burning & 6 & 7.6 & 20 & 20 & \\
\hline
\end{tabular}

Key: ${ }^{a}=$ river, pond, unprotected well $^{\mathrm{b}}=$ public tap, private tape, protected well.

Appropriate infant and young child feeding has been identified as one of the key determinants of child malnutrition particularly stunting [41]. In the current study, inappropriate exclusive breastfeeding children were more likely to be stunted compared to their counterparts. This result is agreed with studies conducted in rural Dubit district, Arba Minch, and Nepal [42-44]. This might be early initiation and exclusive breastfeeding for 6 months of life meets the energy and nutrient needs of the vast majority of infants and provides protection against gastrointestinal infections, which can lead to severe nutrient depletion and stunting [45]. Furthermore, after 6 months breast milk alone is not sufficient to meet the nutritional requirements. Both earlier and delayed introduction of complementary food predisposes the child to increased risks of growth faltering [46].

This study also showed that children with diarrhea exposure in the past two weeks were more likely to be stunted compared to those children with no exposure. This finding is in line with the finding of studies conducted in Kindo Didaye district, Bule Hora district, Angolela Tera District, and Kenya [47-50]. The possible explanation might be increased exposure to infections associated with taking other fluids, solids, and ingestion of contaminated materials as the children start exploring their environment. Diarrhea affects children's nutritional status by diminishing appetite, reducing nutrient absorption, increasing metabolic requirements, and increasing nutrient losses [51].

\section{Limitation of the study}

This study had several strengths. Among these, many variables considered to be risk factors of stunting were assessed and a pre-tested and valid questionnaire was used to collect information. The case-control nature of this study is stronger than a cross-sectional study in assessing risk factors which is important to develop a relevant policy strategy for efficient prevention of stunting. Regardless of its strengths, our study had some basic limitations that might be considered while interpreting the results. First, the study might be prone to recall bias because the study was based on a self-report of questions that require a good memory of mother's/ care giver. Second, the study is predisposed to errors of anthropometric measurement that might lead to misclassification of children's nutritional status. Third, the WASH variables were not significantly associated with stunting. This is due to there is a possibility of reporting bias both from respondents and data collectors. Cognizant of this, data collectors were told during the training to properly ask WASH variables and to elicit a genuine response from the respondents. Fourth, similar to several other observational studies, we controlled for potential confounders using the multivariable logistic regression model. However, we were not considered all possible risk factors of stunting due to the resource and time shortage. Moreover, we did not collect data on food security, minimum dietary diversity score, and the occurrence of intestinal helminths on infections 
Table 6 Bi-variable and multivariable logistic regression analysis of the factors associated with stunting among children aged 6-59 months in the Bensa district, Sidama Region, South Ethiopia, 2018

\begin{tabular}{|c|c|c|c|c|}
\hline Variables & Cases & Controls & $\operatorname{COR}(95 \% \mathrm{Cl})$ & AOR(95\%Cl) \\
\hline \multicolumn{5}{|l|}{ Sex of children } \\
\hline Male & 52 & 72 & $2.300(1.313-4.029)^{* *}$ & $2.37(1.224-4.59)^{*}$ \\
\hline Female & 27 & 86 & 1 & 1 \\
\hline \multicolumn{5}{|l|}{ Total family size } \\
\hline$\geq 5$ & 46 & 70 & $1.752(1.015-3.036)^{*}$ & $.492(.174-1.389)$ \\
\hline$<5$ & 33 & 88 & 1 & 1 \\
\hline \multicolumn{5}{|l|}{ Number of $<5$ year children } \\
\hline $2-3$ & 40 & 47 & $2.422(1.387-4.230)^{* *}$ & $2.18(1.03-4.64)^{*}$ \\
\hline 1 & 39 & 111 & 1 & 1 \\
\hline \multicolumn{5}{|l|}{ Maternal educational status } \\
\hline Has no formal education & 45 & 48 & $3.712(2.041-6.753)^{* * *}$ & $3.28(1.56-6.924)^{* *}$ \\
\hline Can read \& write & 9 & 11 & $3.240(1.211-8.669)^{*}$ & $2.752(.897-8.446)$ \\
\hline Has formal education & 25 & 99 & 1 & 1 \\
\hline \multicolumn{5}{|l|}{ Wealth Index } \\
\hline Poor & 41 & 53 & $2.689(1.427-5.068)^{* *}$ & $1.169(.538-2.539)$ \\
\hline Medium & 17 & 32 & $1.847(.861-3.959)$ & $.906(.360-2.281)$ \\
\hline Rich & 21 & 73 & 1 & 1 \\
\hline \multicolumn{5}{|l|}{ Diarrhea, preceding 2wks } \\
\hline Yes & 44 & 51 & $2.638(1.514-4.596)^{* *}$ & $2.71(1.42-5.162)^{* *}$ \\
\hline No & 35 & 107 & 1 & 1 \\
\hline \multicolumn{5}{|l|}{ Duration of EBF } \\
\hline$<6$ or $>6$ months & 45 & 52 & $2.698(1.548-4.702)$ & $2.07(1.06-4.01)^{*}$ \\
\hline 6 months & 34 & 106 & 1 & 1 \\
\hline \multicolumn{5}{|l|}{ Source of drinking water } \\
\hline Unprotected & 32 & 43 & $1.821(1.030-3.219)$ & $1.446(.738-2.833)$ \\
\hline Protected & 47 & 115 & 1 & 1 \\
\hline
\end{tabular}

Key: 1 : Reference category; ${ }^{*}=P<.05 ;{ }^{* *}: P<.005 ;{ }^{* * *} P<.001 ;$ COR Crude Odds Ratio, AOR Adjusted Odds Ratio, $C I$ Confidence Interval

that could contribute to the increased prevalence of malnutrition.

\section{Conclusions}

The number of under-five year old children in the household, sex of a child, mother's educational status, inappropriate exclusive breastfeeding, and diarrhea in the past 2 weeks were significant associated factors with stunting.

This study finding has serious policy implications because it provides a basis for expanding stunting reduction interventions in rural areas to include not only nutritional but also personal hygiene and environmental sanitation measures. The appropriate infant and young child feeding, maternal education, birth spacing, and healthier environment of the child with reduced exposure to bacteria have a substantial potential to further reduce stunting.

Therefore, the Bensa district health office should encourage mothers to space birth between children through the use of family planning services. Health extension workers shall educate mothers/caretakers on the importance of exclusive breastfeeding. Moreover, the district health office should give priority to personal hygiene and environmental sanitation to prevent diarrhea.

\section{Abbreviations}

AOR: Adjusted odds ratio; Cl: Confidence Interval; EPI: Expanded program for Immunization; GTPII: Growth and transformation plan two; OPD: Out Patient Department; SD: Standard Deviation; SDG: Sustainable Development Goals; OR: Odd ratio; SPSS: Statistical packages for social science; WASH: Water, sanitation and hygiene; WHO: World Health Organization.

\section{Supplementary Information}

The online version contains supplementary material available at https://doi. org/10.1186/s12887-021-03029-9.

Additional file 1. S1 Tool. This is the S1 English version survey questionnaire. 


\section{Acknowledgments}

Authors would like to thank Hawassa University, School of Public Health for approval of ethical clearance. The authors are also very grateful for data collectors and study participants. Finally, our special thanks go to Nana Chea for his genuine support.

\section{Authors' contributions}

TT- Involved in initiation of the research question, prepared the research proposal, carried out the research, did the data entry and analysis, and wrote the manuscript. TG- conducted edition, advising, cooperatively prepared research tools with $\mathrm{Pl}$, and revised the manuscript. KM- conducted edition, advising, and reviewed the manuscript. AY- Did the data entry, analysis, prepared and reviewed the manuscript. All authors have read and approved the final manuscript.

\section{Funding}

The financial aid of this thesis was obtained from Bensa district with specific grant numbers BWH/10123/10. Temesgen Tafesse is the author who received an award. The funded agency did not take part in the thesis design, data collection, and manuscript preparation process.

\section{Availability of data and materials}

The datasets used and/or analyzed during the current study available from the corresponding author on reasonable request.

\section{Declarations}

\section{Ethics approval and consent to participate}

Ethical clearance was obtained from the Institutional Review Board (IRB) at the College of Medicine and Health Sciences of Hawassa University before commencing data collection (Ref. No: IRB/145/10). An official letter of permission was obtained from the Department of Public Health to the respective district health office. Informed written permission was also obtained from the district health office.

The purposes and importance of the study was explained at all levels and written informed consents were secured from each mothers/caretakers. A selected participant was assured that the data couldn't have any negative consequence on any aspects of their life. They were given full right to leave/to refuse to take part at any stage of the interview. Confidentiality was maintained by not exposing or sharing the information gathered from the respondents at all levels of the study. All methods were carried out in accordance with relevant guidelines and regulations.

\section{Consent for publication}

Not applicable.

\section{Competing interests}

All authors declare that they have no conflicts of interest.

\section{Author details}

'Department of Public Health, Hawassa University Daye Branch, Hawassa, Ethiopia. ${ }^{2}$ School of Public Health, College of Medicine and Health Science, Hawassa University Hawassa, Hawassa, Ethiopia.

\section{Received: 27 February 2021 Accepted: 16 November 2021}

Published online: 06 December 2021

\section{References}

1. Becker P, Mark R, Monczka J, Smith E. Consensus statement of the academy of nutrition and dietetics/american society for parenteral and enteral nutrition :indicators recommended for the identification and documentation of pediatric malnutrition (Undernutrition). Nutr Clin Pract. 2014;114:12.

2. Antwi S. Malnutrition: missed opportunities for diagnosis. Ghana Med J. 2008;42(3):101-4.

3. Prendergast AJ, Rukobo S, Chasekwa B, et al. Stunting is characterized by chronic inflammation in Zimbabwean infants. PLoS One. 2014;9:e86928.
4. Development initiatives. Global Nutrition Report: Shining a light to spur action on nutrition.2018. Bristol, UK.

5. UNICEF, WHO,World bank. Levels and trends in child malnutrition. New York; Geneva,Swiztherland; Washingthon,Dc: Joint child malnutrition estimates; 2016.

6. Central Statistical Agency (CSA) [Ethiopia], ICF. Ethiopia Demographic and Health Survey: Key Indicators Report. Addis Ababa, Ethiopia, and Rockville, Maryland, USA: CSA and ICF; 2016.

7. Assefa S, Hailu D, Kabeta A, Berhanu G. Household sanitation practice associated with nutritional status of pre-school children aged 24-59 months in Hawassa Zuria Woreda, South Ethiopia: A cross-sectional study. Curr Pediatr Res. 2017;21(2):291-7.

8. WHO. The Lancet's Series on Maternal and Child Undernutrition, 2008. Available online from https://apps.who.int/nutrition/publications/ lancetseries_maternal_and_childundernutrition/en/index.html.

9. World Health Organization. Comparative Quantification of Health Risks in Global and Regional Burden of Disease Attributable to Selected Major Risk Factors. Geneva: World Health Organization; 2014

10. Joseph $\mathrm{M}$. The potential impact of reducing global malnutrition on poverty reduction and economic development. Asia Pac J Clin Nutr. 2005;14(CD Supplement):10-38.

11. World Health Organization. Nutrition Landscape Information System (NLIS) Country Profile Indicators: WHO Document Production Services; 2010.

12. Black RE, Morris SS, B. J. Where and why are 10 million children dying every day? Lancet. 2003;361:2226-34.

13. United Nations Childrens Fund. UNICEF's approach to scaling up nutrition for mothers and their children. New York: Discussion paper Programme Division; 2015.

14. Panter-Brick C, Lunn PG, Langford RM, et al. Pathways leading to early growth faltering: an investigation into the importance of mucosal damage and immune stimulation in different socio-economic groups in Nepal. Br J Nutr. 2009;101:558-67.

15. International Food Policy Research Institute. 2016. Global Nutrition Report 2016: From Promise to Impact: Ending Malnutrition by 2030 Washington, D.C.: https://doi.org/10.2499/9780896295841.

16. Government of Federal Democratic Republic of Ethiopia. National Nutrition Programme. June 2013 - June 2015. 2013. Available online from https://www.academia.edu/36267071/National_Nutrition_Progr amme.

17. Federal Democratic Republic of Ethiopia. Food and Nutrition Policy.2018.

18. Alemu M, Nicola J, Bekele T. Tackling Child Malnutrition in Ethiopia. Young lives project working. 2005. 9. Available online from https://www.young lives.org.uk/content/tackling-child-malnutrition-ethiopia.

19. Federal Democratic Republic of Ethiopia. Growth and Transformation Plan II (GTP II). (2015/16-2019/20). Addis Ababa: National Planning Commission; 2016.

20. Jie H, Ming F, Nair S. Risk factors of malnutrition among preschoolchildren in Terengganu,Malaysia: a case control study. BMC Public Health. 2014; 14:785.

21. Zoran B, Heath G, David KW, David WH. Purposeful selection of variables in logistic regression. Source Code for Bio Med. 2008;3:17.

22. Fikadu T, Assegid S, Dube L. Factors associated with stunting among children of age 24 to59 months in Meskan district, Gurage Zone, South Ethiopia: a case-control study. BMC Public Health. 2014;14:800.

23. Berhe K, Seid O, Gebremariam Y, Berhe A, Etsay N. Risk factors of stunting (chronic undernutrition) of children aged 6 to 24 months in Mekelle City, Tigray Region, North Ethiopia: An unmatched case-control study. PLoS One. 2019;14(6):e0217736. https://doi.org/10.1371/journal.pone.0217736.

24. Maria L, Cruz G, González G, Reyes D, et al. Factors associated with stunting among Children aged 0 to 59 months from the Central Region of Mozambique. Nutrients. 2017:9:491.

25. Nair R, et al. Linkage between family planning and nutrtion: Futers Group,Health policy Project; 2015.

26. Birhanu A, et al. Stunting and risk factors among children aged 6-59 months in Lasta district, North East Ethiopia, 2015: a community-based cross sectional study design. J Fam Med. 2017;4(3):1112.

27. Shine S, Tadesse F, Shiferaw Z, Mideksa L, et al. Prevalence and risk factors of Stunting among 6-59 months children in the pastoral community of Korahay Zone, Somali Regional State, Ethiopia. J Nutr Disord Ther. 2017:7:1. 
28. Solomon D, Amare W. Magnitude and factors associated with malnutrition in children 6-59 months of age in pastoralcommunity of Dollo Ado District, Somali Region, Ethiopia. Sci J Public Health. 2013;1(4):175-83.

29. Amare M, Lemma D, Adhanom G, Erkihun T. Risk factors of stunting among children age 6-59 months in Ethiopia using Bayesian multi-level analysis. Sci Rep. 2021;11:3759.

30. John B, et al. Risk factors of stunting in children aged 6 to 59 month: A Case-control study in Southwest Uganda. Food Nutr Bull. 2017:38(4):542-53.

31. Kingsley E R, Kerry J, Steven J, et al. Prevalence and risk factors for stunting and severe stunting among under-fives in North Maluku province of Indonesia. BMC Pediatr. 2009;9:64.

32. Jonathan C. Natural selection and sex differences in morbidity in early life. J Theor Biol. 2000;202(1):5-76.

33. Abeway S, Gebremichael B, Murugan R, Assefa M, Adinew YM. Stunting and Its Determinants among Children Aged 6-59 Months in Northern Ethiopia: A Cross-Sectional Study. J Nutr Metab. 2018;2018:1078480. https://doi.org/10.1155/2018/1078480.

34. Mushtaq S, Gull U, Khurshid U, Shahid M, et al. Prevalence and sociodemographic correlates of stunting and thinness among Pakistani primary school children. BMC Public Health. 2011;11(1):790.

35. Moges B, Feleke A, Meseret S, Doyere F. Magnitude of stunting and risk factors among 59months old children in Hossana Town, Southern Ethiopia. J Clinic Res Bioeth. 2015;6:1.

36. Wamani H, Tylleskär T, Åstrøm A, Tumwine J, et al. Mothers' education but not fathers' education, household assets or land ownership is the best predictor of child health inequalities in rural Uganda. Int J Equity Health. 2004;3(1):9.

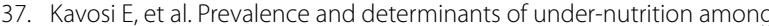
children under six: A cross-sectional survey in Fars province, Iran. Int J Health Policy Manag. 2014;3(2):71.

38. Abuya A, Ciera J, Marage K. Effect of mother's education on child's nutritional status in the slums of Nairobi.BMC. Pediatrics. 2012;12:80.

39. Dara W, Deska S, Gusnedi. Risk factors in the event of stunting children age 24-59 month case study in Kelurahan Balai Gadang,Health center of Air Dingin Padang City in 2015: Riau International Nursing Conference; 2015.

40. Bhagowalia P, Menon P, Quisumbing AR, Soundararajan V. What dimensions of womens empowerment matter most for child nutrition? Evidence Using Nationally Representative Data from Bangladesh. IFPRI Discussion Paper 1192. Washington, D.C.: International Food Policy Research Institute (IFPRI). 2012. http://ebrary.ifpri.org/cdm/ref/collection/ p15738coll2/id/127005.

41. Stewart CP, lannotti L, Dewey KG, Michaelsen KF, Onyango AW. Contextualising complementary feeding in a broader framework for stunting prevention. Matern Child Nutr. 2013;9(2):27-45.

42. Molla K, Etsay W, Abel G, Surender R. Determinants of stunting among children aged 6 to 59 months in pastoral community, Afar region, North East Ethiopia: unmatched case control study. BMC Nutr. 2020;6(9):2-8.

43. Bogale B, Gutema BT, Chisha Y. Prevalence of Stunting and Its Associated Factors among Children of 6-59 Months in Arba Minch Health and Demographic Surveillance Site (HDSS), Southern Ethiopia: A CommunityBased Cross-Sectional Study. J Environ Public Health. 2020;2020:9520973. https://doi.org/10.1155/2020/9520973.

44. Paudel $\mathrm{R}$, et al. Risk factors for stunting among children: a community based case control study in Nepal. Kathmandu Univ Med J. 2012;39(3):18-24.

45. Butte N, Lopez-Alarcon MG, Garza C. Nutrient adequacy of exclusive breastfeeding for the term infant during the first six months of life. Geneva: World Health Organization; 2002.

46. UNICEF. UNICEF Programming Guide: Infant and Young Child Feeding. Emergency Nutrition Network (ENN). 2011. Available online from https:// www.ennonline.net/unhcriycfprogrammingguide.

47. Batiro B, Demissie T, Halala Y, Anjulo AA. Determinants of stunting among children aged 6-59 months at Kindo Didaye woreda, Wolaita Zone, Southern Ethiopia: Unmatched case control study. PLoS One. 2017;12(12):e0189106. https://doi.org/10.1371/journal.pone.0189106.

48. Mandefro A, Mekitie W, Mohammed T, Lamessa D. Prevalence of undernutrition and risk factors among children aged between six to fifty nine months in Bule Hora district, South Ethiopia. BMC Public Health. 2015:15:41.
49. Mengiste L, Worku Y, Aynalem A, Shiferaw S. Prevalence of stunting and its associated factors among children aged 6-59 months in Angolela Tera District, Northeast Ethiopia. Nutr Dietary Suppl. 2020;12:311-9.

50. Park K, et al. Trends and determinants of undernutrition among young Kenyan children: Kenya Demographic and Health surve; 1998, 2003 and 2008-2009. Public Health Nutr. 2012;15(9):1715-27.

51. Vu Thi Nguyet A, Chompikul J, Isaranurug S. Relationship between stunting and food provided to children aged from 6 to 24 months in Soc Son District, Hanoi, Vietnam. J Public Health Dev. 2009;7(3):44-58.

\section{Publisher's Note}

Springer Nature remains neutral with regard to jurisdictional claims in published maps and institutional affiliations.

Ready to submit your research? Choose BMC and benefit from:

- fast, convenient online submission

- thorough peer review by experienced researchers in your field

- rapid publication on acceptance

- support for research data, including large and complex data types

- gold Open Access which fosters wider collaboration and increased citations

- maximum visibility for your research: over $100 \mathrm{M}$ website views per year

At BMC, research is always in progress.

Learn more biomedcentral.com/submissions 